\title{
VIABILIDADE E SUPERAÇÃO DA DORMÊNCIA EM SEMENTES DE ARAÇÁ-BOI (Eugenia stipitata ssp. sororia)
}

\author{
Daniel Felipe de O. GENTIL', Sidney Alberto do N. FERREIRA ${ }^{2}$
}

\begin{abstract}
RESUMO - O araçá-boi (Eugenia stipitata ssp. sororia McVaugh - Myrtaceae) è uma frutífera amazônica com potencial agroindustrial. O presente trabalho verificou os efeitos da desidrataçào sobre a viabilidade de sementes e avaliou métodos de escarificação mecânica (por descascamento e lixamento) na superação da dormência de sementes dessa espécie. A qualidade fisiológica das sementes é afetada pela redução do teor de água. As sementes apresentam comportamento recalcitrante, sendo que o nivel crítico de umidade pode estar situado entre 58,8 e $47,1 \%$. A desidratação a niveis iguais ou inferiores a $25,76 \%$ de água provocou a morte em $100 \%$ das sementes. As sementes devem ser semeadas, preferencialmente, logo após a extração e limpeza. O tegumento das sementes apresenta resistência mecânica à expansão do embrião. A remoção total do tegumento foi o método mais eficiente na superação da dormência, pois elimina a resistência na regiào onde ocorrerá a ruptura pelo embrião, com tempo médio de emergência de 66 dias e percentagem final de emergência de $96 \%$. Os lixamentos provocaram injúrias mecânicas nas sementes, tendo conseqüências diretas na emergência e vigor.
\end{abstract}

Palavras chave: fisiologia de sementes, teor de água, recalcitrante, escarificação mecânica.

Viability and Overcoming Dormancy in Seeds of Araçá-Boi (Eugenia stipitata ssp. sororia).

ABSTRACT - Eugenia stipitata ssp. sororia McVaugh - Myrtaceae is a small Amazonian fruit tree with considerable economic potential. The present work investigated the effects of dehydration on seed viability and evaluated methods of overcoming seed dormancy by mechanical scarification (by peeling and sanding). The physiological quality of seeds is affected by reduction in moisture content. Seeds show recalcitrant behaviour with a critical moisture content between 58,8 and $47,1 \%$. No seeds survived dehydration to moisture contents of less than or equal to $25,76 \%$. In view of the detrimental effects of drying, seeds should preferably be sown immediately after being extracted and cleaned. The seed integument offers mechanical resistance to expansion of the embryo. Total removal of the integument proved to be the most efficient method of overcoming dormancy since it climinates resistance in the region where the embryo normally breaks through. The average time for emergence was 66 days and the final percentage emergence was $96 \%$. Simple abrasion of the integument caused mechanical injury to the seeds with adverse consequences on emergence and vigour.

Key-word: Seed physiology, moisture content, recalcitrant, mechanical scarification.

\section{INTRODUÇÃO}

O araçá-boi (Eugenia stipitata ssp. sororia McVaugh - Myrtaceae) é uma espécie frutífera nativa da Amazônia que apresenta grandes possibilidades de ser cultivada em escala comercial, visando o aproveitamento da polpa do fruto na elaboração de refresco, geléia, creme e sorvete (Chavez \& Clement,
1984). Apesar da facilidade de cultivo, o araçá-boi possui duas características fisiológicas que exigem cuidados no processo de formação de mudas: o periodo de viabilidade relativamente curto e a dormência de suas sementes. Conforme Pinedo et al. (1981), quando postas a secar, sob condições de ambiente à sombra, as sementes de araçá-boi começam a perder a viabilidade a partir

\footnotetext{
Mestrando em Fitotecnia, ESALQ/USP, Av. Pádua Dias, 11, Cx. Postal 9, CEP. 13418-900, Piracicaba-SP.

2 Pesquisador, INPA/CPCA, Caixa Postal 478, CEP. 69011-970, Manaus - AM.
} 
de 24 horas, mostrando um poder germinativo de $70 \%$ após 5 dias.

O período de viabilidade é determinado, a principio, geneticamente, porém, pode ser alterado pelos fatores ambientais que cercam a semente. Geralmente, é mais bem mantido sob condições nas quais sua atividade metabólica é reduzida, ou seja, conservando-a com baixo teor de água, sob baixa temperatura e alta concentração de dióxido de carbono (Popinigis, 1977).

A maioria das espécies tem sementes cujo periodo de viabilidade pode ser estendido pela diminuição do seu teor de água e da temperatura de armazenamento. Em tais sementes, o teor de água pode ser reduzido até 2 - 5\%. Essas sementes foram classificadas por Roberts (1973) como ortodoxas. Existe, entretanto, outro grupo menos numeroso de espécies cuja sementes normalmente não toleram desidratação e baixas temperaturas de armazenamento, chamadas recalcitrantes (Roberts, 1973). Nessas, a redução do teor de água à niveis abaixo de um valor relativamente elevado, algo entre 12 e $31 \%$, dependendo da espécie, tende a diminuir o período de viabilidade. Mais recentemente foi determinado um terceiro grupo, com comportamento intermediário entre as sementes ortodoxas e recalcitrantes (Ellis et al., 1990).

As sementes de muitas espécies germinam rápida e uniformemente, sob condições ambientais favoráveis. Todavia, algumas apresentam um mecanismo que retarda e distribui no tempo a germinação de suas sementes, denominado dormência (Popinigis, 1977). No caso do araçá-boi, um lote de sementes pode levar 45 a 90 dias para começar a germinar e 180 a 270 dias para terminar, com percentagem final de 80 a 90\% (Chavez \& Clement, 1984). O embrião das sementes dessa espécie é conferruminado (Flores \& Rivera, 1989) e não diferenciado (McVaugh, 1956).

A razão da dormência de sementes de diversas espécies da floresta tropical pode ser: o embrião imaturo ou rudimentar; a impermeabilidade do tegumento à água ou às trocas gasosas; a resistência mecânica do tegumento à expansão do embrião; a presença de inibidores; e a combinação de causas (Popinigis, 1977). Segundo Pinedo et al. (1981), a dormência das sementes de araçá-boi é causada pelo tegumento, que ao secar torna-se resistente à ruptura pelo embrião; por isso, recomendam sua remoção com o auxílio de um objeto cortante.

$\mathrm{O}$ presente trabalho foi elaborado com a finalidade de verificar os efeitos da desidratação sobre a viabilidade de sementes e de avaliar métodos de escarificação mecânica na superação da dormência de sementes de araçá-boi.

\section{MATERIAL E MÉTODOS}

Os experimentos foram conduzidos nas dependências da Coordenação de Pesquisas em Ciências Agronômicas (CPCA), do Instituto Nacional de Pesquisas da Amazônia (INPA), em Manaus - Amazonas $\left(03^{\circ} 08^{\prime} \mathrm{S} ; 60^{\circ} 02^{\prime} \mathrm{W}\right)$. $\mathrm{O}$ comportamento de alguns fatores climáticos durante o periodo de desenvolvimento dos ensaios está representado na Figura 1.

Experimento 1: viabilidade das sementes (realizado no periodo de janeiro a novembro de 1991). 


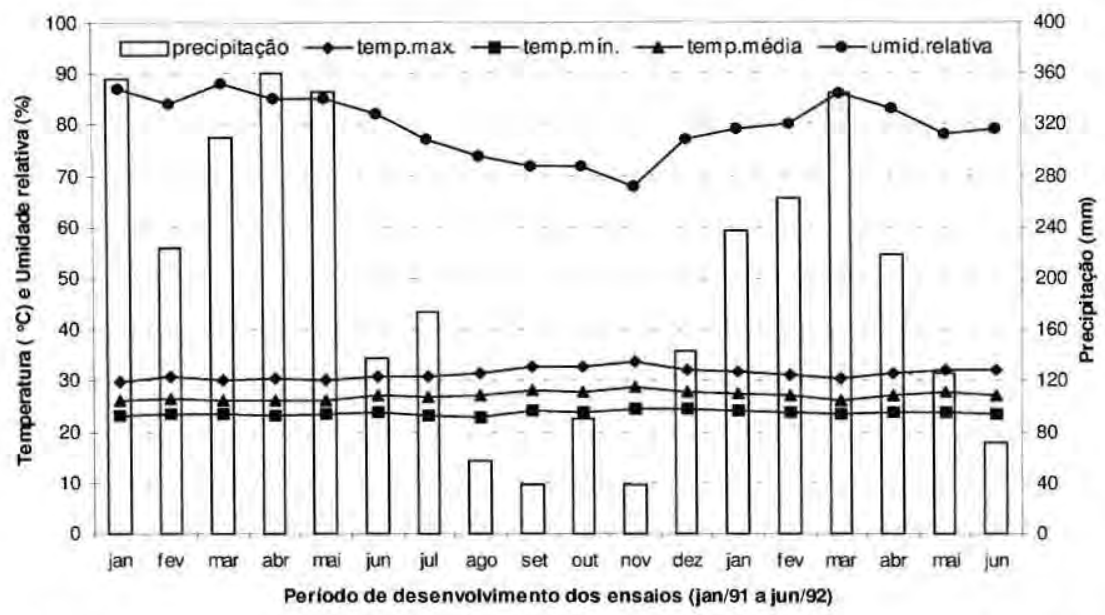

Figura 1. Comportamento da umidade relativa, precipitação e temperaturas (média das máximas - temp.max., média das minimas - temp.mín. e média compensada - temp.média) durante o periodo de desenvolvimento dos ensaios com sementes de araçá-boi: dados fornecidos pelo INMET $-1^{\circ}$ Distrito de Meteorologia, Manaus - AM.

Inicialmente foram coletados frutos maduros de plantas cultivadas na área da CPCA. Após a extração manual, as sementes permaneceram imersas em água por 48 horas, para facilitar a retirada do resto de polpa e tecido placentário que ficaram aderidos ao tegumento, sendo feita a troca diária da água. Passado esse periodo, foram submetidas à friç̧ão manual com areia e serragem peneiradas (para 1 volume de semente, $1 / 2$ de serragem e $1 / 2$ de areia) e lavagem em água corrente, com pressão sobre peneira, até ficarem completamente limpas. Em seguida, foram imersas em solução de hipoclorito de sódio a $1 \%$ por 15 minutos e então postas a secar à sombra sob condições de meio ambiente (temperatura média aproximada de $26^{\circ} \mathrm{C}$ e umidade relativa do ar ao redor de $85 \%$ ).

Aos 1, 3, 5, 7, 9 e 11 dias de secagem natural, foram retiradas amostras para a determinação do teor de água, com 4 repetições de 15 sementes cada, e para a semeadura, com 4 repetições de 25 sementes cada. Adeterminação do teor de água foi baseada no método de estufa a $105 \pm 3^{\circ} \mathrm{C}$ por 24 horas, com cálculo feito na base úmida (Brasil, 1992). A semeadura foi realizada em caixas de madeira, tendo como substrato serragem parcialmente decomposta e peneirada (Ferreira, 1989), alocadas em viveiro com $50 \%$ de luminosidade. A profundidade e o espaçamento de semeadura foram de $2 \mathrm{~cm}$. A irrigação foi executada sempre que necessário, mantendo o substrato úmido.

A emergência das plântulas foi observada a cada cinco dias, a partir do aparecimento da parte aérea acima do nível do substrato. Aos nove meses da semeadura, depois de não ser evidenciada nenhuma emergência por um periodo de 10 dias desde a última 
observação, foi encerrado o experimento, quando foram avaliados a altura da parte aérea, o diâmetro do colo, o número de folhas e o peso da matéria seca de 10 plântulas por parcela, escolhidas ao acaso. O peso da matéria seca foi avaliado em plântulas submetidas a secagem em estufa a $75^{\circ} \mathrm{C}$ por 48 horas.

$\mathrm{O}$ índice de velocidade de emergência (IVE) foi determinado de acordo com a proposta de Maguire (1962), sendo que para efeito de cálculo, ao invés de utilizar o número de sementes germinadas, foi empregado o percentual de plântulas emergidas.

Experimento 2: dormência das sementes (realizado no periodo de novembro de 1991 a junho de 1992).

Quanto a colheita, beneficiamento e tratamento fitossanitário, as sementes utilizadas neste ensaio seguiram os mesmos procedimentos descritos para 0 experimento anterior. Exceção do tempo de permanência das sementes submersas em água, para facilitar a limpeza, que aqui, por conveniência, foi de 96 horas, também com troca diária da água.

Após o tratamento com hipoclorito de sódio, as sementes foram secas à sombra, sob condições de meio ambiente, por 48 horas, quando então foram aplicados os tratamentos que se seguem: testemunha - sementes intactas; lixamento em um dos lados da semente; lixamento nos dois lados da semente; descascamento em um dos lados da semente; descascamento nos dois lados da semente; e descascamento total da semente. Os lixamentos foram realizados em pedra abrasiva até atingir o cotilédone. Os descascamentos foram feitos com bisturi inoxidável. As sementes dos diferentes tratamentos ficaram imersas em água durante a aplicação dos métodos de escarificação mecânica, correspondendo a 11 horas de imersão. Por tratamento foram utilizadas 4 repetições de 25 sementes cada.

Seguido a aplicação dos tratamentos, as sementes foram semeadas sob as mesmas condições do primeiro experimento, tendo a emergência sido acompanhada por um período de seis meses, quando foi observado uma tendência de estabilização dos resultados. As variáveis avaliadas também foram as mesmas já descritas, acrescentando o tempo médio de emergência (TME), calculado de acordo com Edwards (1934).

Nos dois ensaios, o delineamento empregado foi inteiramente casualizado, obedecendo o número de tratamentos de cada um, sendo as médias comparadas pelo teste de Tukey ao nivel de $5 \%$ de probabilidade. Para efeito de análise, os dados de emergência foram transformados em arco seno raiz quadrada de $\mathrm{x} / 100$ e os dados de tempo médio de emergência e número de folhas de plântulas em raiz quadrada de X, conforme Centeno (1990).

\section{RESULTADOS E DISCUSSÃO}

Experimento 1: viabilidade das sementes

As médias de teor de água de sementes e de percentagem de emergência, correspondentes a 1 dia de secagem, foram estatisticamente superiores, respectivamente, às médias relativas a $3,5,7,9$ e 11 dias. Por outro lado, não houve diferença significativa entre as médias de teor de água nos períodos de 9 e 11 dias, o mesmo ocorrendo entre as médias de 
percentagem de emergência nos períodos de 7, 9 e 11 dias.

A redução no teor de água das sementes implicou na diminuição acentuada da percentagem de emergência (Fig. 2), principalmente do terceiro ao quinto dia de secagem natural. Com $58,8 \%$ de água ( 1 dia de secagem) ocorreu emergência de $80 \%$; quando o teor de água caiu para $47,1 \%$ (3 dias de secagem), a emergência foi reduzida para $59 \%$; com $35,2 \%$ de água (5 dias de secagem) a emergência foi de $20 \%$; a partir dos 7 dias de secagem, oumelhor, com teor de água de $25,8 \%$, praticamente não ocorreu emergência. Correlacionando o teor de água com a emergência das sementes de araçá-boi, obteve-se um índice positivo e significativo ao nivel de $1 \%$ de probabilidade $(\mathrm{r}=0,98)$, reafirmando que quanto menor for teor de água das sementes, menor será a germinação das mesmas.

Os resultados obtidos evidenciaram os efeitos prejudiciais da desidratação sobre a emergência das plântulas de araçá-boi e comprovaram as observações de Pinedo et al. (1981). Sementes de muitas espécies de típica adaptação ecológica tropical também perdem a viabilidade tanto mais rapidamente quanto mais desidratadas (Carvalho \& Nakagawa, 1983), como foi verificado em Hevea brasiliensis (Willd. ex Adr. de Juss.) Muell. Arg. (Chin et al., 1981) e em Paullinia cupana var. sorbilis (Mart.) Ducke (Carvalho et al., 1982).

As sementes de araçá-boi não toleraram desidratação a níveis iguais ou inferiores a $25,8 \%$ de água, perdendo totalmente o seu poder germinativo. Resultados semelhantes foram obtidos por Casas \& Ibañes (1964), em sementes de Theobroma cacao L. com 16\% de água, e por Andrade (1994), com sementes de Euterpe edulis Mart., E. oleracea Mart., E. catinga A. R. Wallace, Oenocarpus bacaba Mart. e $O$. minor Mart. quando desidratadas a aproximadamente $20-24 \%$ de água, confirmando a sensibilidade das sementes dessas espécies à desidratação. Corbineau \& Côme (1988) observaram que as sementes de Shorea roxburghii G.

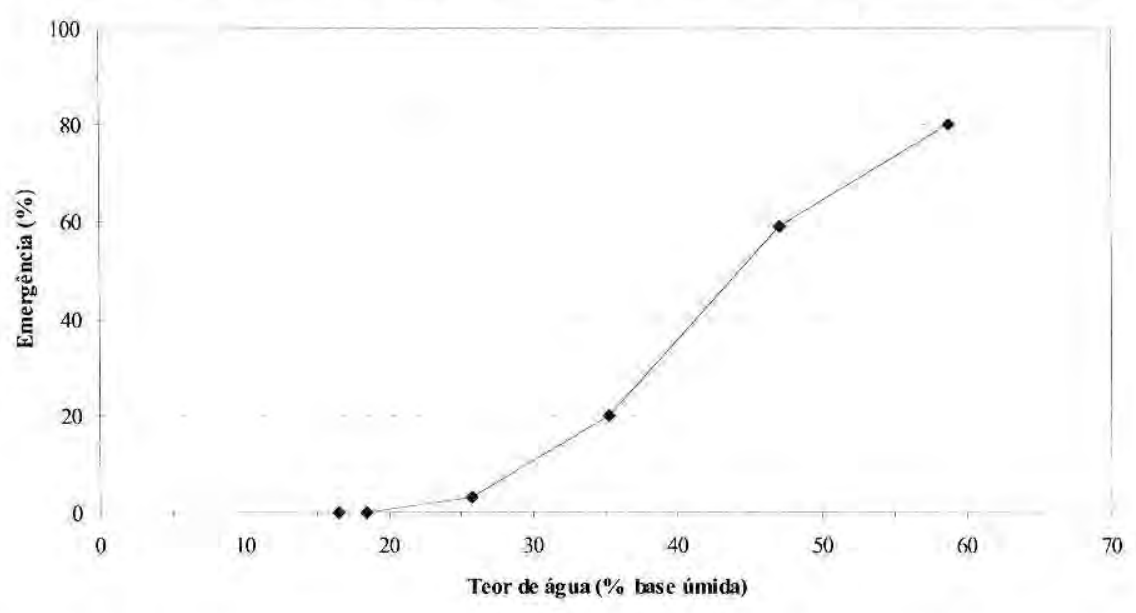

Figura 2. Relação entre o teor de água das sementes e emergência das plântulas de araçá-boi. 
Don, Hopea odorata Roxb., Mangifera indica L. e Symphonia globulifera L. morreram quando seu teor de água foi reduzido a $14,5 \%, 14,5 \%, 23,1 \%$ e $27,0 \%$, respectivamente. Por isso, parecem ser sementes tipicamente recalcitrantes.

A redução no teor de água das sementes de araçá-boi causou também uma perda de vigor (Tab. 1). Assim, a diminuição no teor de água das sementes de $58,8 \%$ (1 dia de secagem) para $47,1 \%$ (3 dias), acarretou redução no índice de velocidade de emergência. Porém, nesta faixa de perda do teor de água, a altura, o diâmetro do colo, o número de folhas e o peso da matéria seca das plântulas mantiveram-se inalterados (Tab. 1). A redução no teor de água de $47,1 \%$ para $35,2 \%$ (do terceiro para o quinto dia de secagem) provocou danos irreversiveis ao vigor das sementes de araçá-boi.

A sensibilidade à desidratação é o principal critério para a identificação de sementes recalcitrantes. Uma forma de testar e identificar sementes recalcitrantes é através de estudos de secagem de sementes, seguidos de testes de germinação, para encontrar o nível crítico de umidade, quando inicia a perda da viabilidade das sementes. Em sementes de Euterpe edulis o decréscimo da percentagem de germinação e do vigor é iniciado após a redução do teor de água para 29\% (Andrade \& Malavasi, 1994). Akoroda (1986) constatou que o teor crítico de água para sementes de Telfairia occidentalis Hook. f. está entre 40 e $60 \%$, atingido do quinto ao oitavo dia de secagem em laboratório.

As sementes de araçá-boi apresentam comportamento recalcitrante de acordo com a classificação proposta por Roberts (1973) e com os resultados obtidos neste estudo. $\mathrm{O}$ nível crítico de umidade pode estar situado entre 58,8 e $47,1 \%$, alcançado aos 1 - 3 dias de secagem natural, pois é o intervalo onde se inicia a perda da viabilidade das sementes. Assim, seguindo as recomendações de Stubsgaard (1989) para o manuseio de sementes

Tabela 1. Vigor de sementes de araçá-boi avaliado através do indice de velocidade de emergência (IVE), altura, diâmetro do colo, número de folhas e peso da matéria seca de plântulas, após diferentes periodos de secagem sob condições de meio ambiente'.

\begin{tabular}{lccccc}
\hline $\begin{array}{l}\text { Dias de secagem } \\
\text { (teor de água) }\end{array}$ & IVE & $\begin{array}{c}\text { ALTURA } \\
(\mathrm{cm})\end{array}$ & $\begin{array}{c}\text { DIÂMETRO } \\
\text { DO COLO } \\
(\mathrm{mm})\end{array}$ & $\begin{array}{c}\text { NÚMERO } \\
\text { DE FOLHAS }\end{array}$ & $\begin{array}{c}\text { PESO DA } \\
\text { MATÉRIA } \\
\text { SECA }(\mathrm{g})\end{array}$ \\
\hline $1(58,8)$ & $0,604 \mathrm{a}$ & $12,93 \mathrm{a}$ & $1,19 \mathrm{a}$ & $24,1 \mathrm{a}$ & $0,149 \mathrm{a}$ \\
$3(47,1)$ & $0,380 \mathrm{~b}$ & $11,60 \mathrm{a}$ & $1,13 \mathrm{a}$ & $19,2 \mathrm{a}$ & $0,116 \mathrm{a}$ \\
$5(35,2)$ & $0,124 \mathrm{c}$ & $5,90 \mathrm{~b}$ & $0,59 \mathrm{~b}$ & $9,6 \mathrm{~b}$ & $0,068 \mathrm{~b}$ \\
$7(25,8)$ & $0,004 \mathrm{~d}$ & $0,74 \mathrm{c}$ & $0,08 \mathrm{c}$ & $1,2 \mathrm{c}$ & $0,008 \mathrm{c}$ \\
$9(18,5)$ & $0,000 \mathrm{~d}$ & $0,00 \mathrm{c}$ & $0,00 \mathrm{c}$ & $0,0 \mathrm{~d}$ & $0,000 \mathrm{c}$ \\
$11(16,4)$ & $0,000 \mathrm{~d}$ & $0,00 \mathrm{c}$ & $0,00 \mathrm{c}$ & $0,0 \mathrm{~d}$ & $0,000 \mathrm{c}$ \\
\hline C.V. $(\%)$ & 21,68 & 16,27 & 11,48 & $17,35^{2}$ & 29,32 \\
\hline
\end{tabular}

1 - Na coluna, médias seguidas de mesma letra não diferem entre si pelo Teste de Tukey, ao nivel de $5 \%$ de probabilidade.

$2-$ C.V. dos dados transformados. 
recalcitrantes, o periodo entre a extração e a semeadura das sementes dessa espécie deve ser o mais curto possivel.

Novos trabalhos podem ser realizados abrangendo outros métodos de secagem (Chin, 1988) para aprimorar o conhecimento sobre a sensibilidade das sementes de araçá-boi à desidratação. Além disso, pode ser testado o grau de tolerância das sementes dessa espécie a baixas temperaturas, uma vez que sensibilidade a baixas temperaturas é outra característica encontrada em algumas sementes recalcitrantes (Chin, 1978).

Experimento 2: dormência das sementes.

Houve diferenças significativas entre os tratamentos adotados em todas as variáveis estudadas. O tratamento descascamento total da semente apresentou os melhores resultados de percentagem final de emergência ( $96 \%$ ), índice de velocidade de emergência $(0,445)$ e tempo médio de emergência de plântulas (66 dias) (Tab. 2), confirmando as conclusões de
Pinedo (1981) e Pinedo et al. (1981) que mediante essa técnica é possível obter um maior número de plântulas em um menor tempo, com percentagem final de germinação em torno de $100 \%$.

Os tratamentos descascamento nos dois lados da semente e descascamento em um dos lados da semente não diferiram estatisticamente da testemunha. Ou seja, as sementes com o tegum - ito removido parcialmente (fora da região onde ocorrerá o rompimento pelo embrião) e as sementes com o tegumento intacto apresentaram as mesmas respostas de percentagem de emergência, índice de velocidade de emergência e tempo médio de emergência, o que vem reforçar a idéia de que o tegumento das sementes de araçá-boi não é impermeável â água e às trocas gasosas. Em sementes de Styzolobium atterrimum Piper \& Tracy, por exemplo, cujo tegumento impede a absorção de água, o tratamento mais efetivo na superação da dormência foi a remoção com bisturi

Tabela 2. Médias de percentagem de emergência, índice de velocidade de emergência (IVE) e tempo médio de emergência (TME) de plântulas, referentes a sementes de araçá-boi submetidas a diferentes métodos de escarificação mecânica'.

\begin{tabular}{|c|c|c|c|}
\hline TRATAMENTO & EMERGÊNCIA (\%) & IVE & TME (dias) \\
\hline Descascamento total & $96 \mathrm{a}$ & $0,445 \mathrm{a}$ & $66 \mathrm{a}$ \\
\hline Descascamento 2 lados & $91 a b$ & $0,304 \mathrm{~b}$ & $89 \mathrm{~b}$ \\
\hline Descascamento um lado & $83 a b$ & $0,273 \mathrm{bc}$ & $90 \mathrm{~b}$ \\
\hline Lixamento 2 lados & $79 \mathrm{~b}$ & $0,224 \mathrm{c}$ & $99 \mathrm{~b}$ \\
\hline Lixamento um lado & $74 \mathrm{~b}$ & $0,204 \mathrm{c}$ & $104 \mathrm{~b}$ \\
\hline Testemunha & $84 a b$ & $0,240 \mathrm{bc}$ & $97 \mathrm{~b}$ \\
\hline C.V. $(\%)$ & $10,13^{2}$ & 11,29 & $4,05^{2}$ \\
\hline
\end{tabular}


de pequena porção do tegumento na região oposta ao eixo embrionário (Maeda \& Lago, 1986).

As sementes submetidas aos lixamentos apresentaram oxidação na superfície desgastada pelo atrito, após a aplicação dos tratamentos, com conseqüências diretas na emergência e vigor (Tabs. 2 e 3). Segundo Carvalho \& Nakagawa (1983), a cicatrização do tecido injuriado consome tempo e energia, o que provoca o retardamento na germinação, bem como a emergência de uma plântula mais fraca. Resultados semelhantes foram verificados em Styzolobium atterrimum (Maeda \& Lago, 1986) e Prosopis juliflora (SW) DC (Bastos et al., 1992), onde os lixamentos foram pouco eficientes na superação da dormência e ainda boa parte das sementes originaram plântulas anormais ou plântulas infectadas.

O tratamento descascamento total da semente apresentou os melhores resultados de vigor de sementes em relação aos demais (Tab. 3). Uma possível explicação para isso seria que as sementes descascadas totalmente não tiveram redução no seu vigor após a aplicação do tratamento e não gastaram energia em cicatrizações de tecidos, o que ocorreu com as sementes lixadas, e ainda não precisaram utilizar parte de suas reservas no rompimento do tegumento pelo embrião, por ocasião da germinação, ao contrário das sementes dos outros tratamentos.

O início da emergência de plântulas no tratamento descascamento total da semente foi aos 31 dias da semeadura e $o$ final aos 169 dias (Fig. 3). Esses resultados diferem dos obtidos por Pinedo et al. (1981), nos quais o início ocorreu aos 21 dias da semeadura e o final aos 110 dias. Mesmo assim, confirmam que o descascamento total favorece a emergência das plântulas de araçá-boi.

Pelas curvas (Fig. 3) é evidente a ação retardadora exercida pelo tegumento sobre a emergência de plântulas. As

Tabela 3. Vigor de sementes de araçá-boi submetidas a diferentes métodos de escarificação mecânica, avaliado através da altura, diâmetro do colo, número de folhas e peso da matéria seca de plântulas '.

\begin{tabular}{lcccc}
\hline TRATAMENTO & $\begin{array}{c}\text { ALTURA } \\
(\mathrm{cm})\end{array}$ & $\begin{array}{c}\text { DIÂMETRO DO } \\
\text { COLO }(\mathrm{mm})\end{array}$ & $\begin{array}{c}\text { NÚMERO DE } \\
\text { FOLHAS }\end{array}$ & $\begin{array}{c}\text { PESO DA MAT. } \\
\text { SECA }(\mathrm{g})\end{array}$ \\
\hline Descascamento total & $20,37 \mathrm{a}$ & $1,94 \mathrm{a}$ & $25,8 \mathrm{a}$ & $0,537 \mathrm{a}$ \\
Descascamento 2 lados & $16,64 \mathrm{ab}$ & $1,68 \mathrm{ab}$ & $20,2 \mathrm{~b}$ & $0,352 \mathrm{~b}$ \\
Descascamento um lado & $18,47 \mathrm{ab}$ & $1,83 \mathrm{ab}$ & $21,5 \mathrm{ab}$ & $0,389 \mathrm{~b}$ \\
Lixamento 2 lados & $16,24 \mathrm{~b}$ & $1,65 \mathrm{ab}$ & $19,5 \mathrm{~b}$ & $0,337 \mathrm{~b}$ \\
Lixamento um lado & $16,51 \mathrm{ab}$ & $1,62 \mathrm{~b}$ & $20,0 \mathrm{~b}$ & $0,319 \mathrm{~b}$ \\
Testemunha & $17,19 \mathrm{ab}$ & $1,62 \mathrm{~b}$ & $21,5 \mathrm{ab}$ & $0,312 \mathrm{~b}$ \\
\hline C.V. $(\%)$ & 10,04 & 7,87 & $4,87^{2}$ & 17,18 \\
\hline
\end{tabular}

1 - Na coluna, médias seguidas de mesma letra não diferem entre si pelo Teste de Tukey, ao nível de $5 \%$ de probabilidade.

2 - C.V. dos dados transformados. 


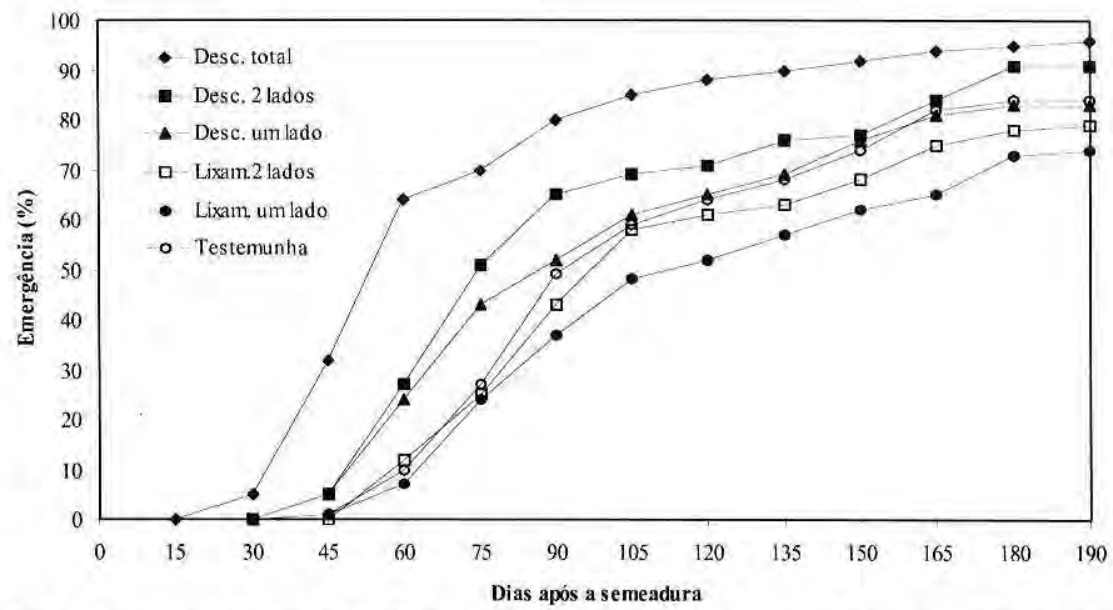

Figura 3. Emergência acumulada de plântulas de araçá-boi referentes a sementes submetidas a diferentes métodos de escarificação mecânica.

sementes desprovidas de tegumento apresentaram antecipação do início da emergência e maior percentagem de emergência de plântulas em um menor período, em comparação aos outros tratamentos. Aroeira (1962) também obteve resultados positivos com a remoção do tegumento/endocarpo de sementes de Persea americana Mill. e Mangifera indica na superação da dormência.

O tegumento das sementes de araçá-boi apresenta resistência mecânica à expansão do embrião. $\mathrm{O}$ descascamento total da semente foi o tratamento mais eficiente, pois elimina a resistência na região onde ocorrerá a ruptura pelo embrião. Pinedo et al. (1981) mencionam que o descascamento deve ser feito com cuidado para não danificar a semente, requerendo certa habilidade que, uma vez alcançada, permite descascar entre 25 a 30 sementes por hora.

No tratamento descascamento total da semente, o início e o término da emergência das plântulas ainda levaram um tempo considerável, sugerindo a existência de outra(s) causa(s) da dormência das sementes de araçá-boi, além da resistência mecânica do tegumento e do embrião conferruminado e rudimentar. Chavez \& Clement (1984) relatam, por exemplo, que sementes intactas dessa espécie mantidas em saco plástico, com carvão vegetal moído úmido, apresentam $100 \%$ de germinação aos 80 - 90 dias. Certamente, outros estudos podem contribuir para um melhor entendimento sobre a dormência das sementes de araçá-boi, em especial os de anatomia e composição quimica de sementes.

\section{CONCLUSÕES}

O presente trabalho permitiu obter as seguintes conclusões sobre as sementes de araçá-boi:

A qualidade fisiológica das sementes é afetada pela redução do teor de água;

As sementes apresentam comportamento recalcitrante, podendo o nível crítico do teor de água estar 
situado entre 58,8 e $47,1 \%$;

As sementes devem ser semeadas, preferencialmente, logo após a extração e limpeza;

$\mathrm{O}$ tegumento das sementes apresenta resistência mecânica à expansão do embrião e sua remoção total foi o procedimento mais eficiente na superação da dormência.

\section{Bibliografia citada}

Akoroda, M. O. 1986. Seed desiccation and recalcitrance in Telfairia occidentalis. Seed Sci.; Technol., 14: 327-332.

Andrade, A. C. S. 1994. Desiccation sensitivity in Brasilian palm seeds. In: International Workshop Desiccation Tolerance and Sensitivity of Seeds and Vegetative Plant Tissues, 1994, Kruger National Park, South Africa. Programme and Abstracts... Kruger National Park: p. 1.

Andrade, A. C. S.; Malavasi, M. M. 1994. Dehydration effects on germination and solute leakage in palmito seeds. In: International Workshop Desiccation Tolerance and Sensitivity of Seeds and Vegetative Plant Tissues, 1994, Kruger National Park, South Africa. Programme and Abstracts... Kruger National Park: p. 2.

Aroeira, J. S. 1962. Dormência e conservação de sementes de algumas plantas frutiferas. Experientiae, 2(3): 541-609.

Bastos, G. Q.; Nunes, R. S.; Cruz, G. M. F. 1992. Reavaliação de quebra de dormência em sementes de algaroba (Prosopis juliflora (SW) DC. Rev. Bras. Sem., 14(1): 17-20.

Brasil. Ministério da Agricultura e Reforma Agrária. 1992. Regras para análise de sementes. Brasilia: $365 \mathrm{p}$.

Carvalho, J. E. U.; Frazão, D, A. C.; Figueiredo, F. J. C.; Oliveira, R. P. 1982. Conservação da viabilidade de sementes de guaraná, Paullinia cupana var. sorbilis (Mart.) Ducke. Belém: EMBRAPA - CPATU. 12 p. (EMBRAPA CPATU, Circular Técnica, 35).
Carvalho, N. M.; Nakagawa, J. 1983. Sementes: ciência, tecnologia e produção. 2. ed. Campinas: Fundação Cargill. 429 p.

Casas, I. A.; Ibañez, M. L. 1964. Relación entre la respiración y la germinación con el contenido de humedad en las semillas de cacao. Turrialba, 14(3): 155-156.

Centeno, A, J. 1990. Curso de estatistica aplicada à biologia. Goiânia: Centro Editorial e Gráfico/UFG. 188 p. (Coleção Didática, 3)

Chavez, W. B.; Clement, C. R. 1984. Considerações sobre o araçá-boi (Eugenia stipitata McVaugh, Myrtaceae) na Amazônia brasileira. In: Congresso Brasileiro de Fruticultura, 7., 1984, Florianópolis. Anais... Florianópolis: Soc. Bras. Fruticultura. p. 167-177.

Chin, H.F. 1978. Production and storage of recalcitrant seed in the tropics. Acta Horticulturae, 83: 17-21.

1988. Recalcitrant seeds: a status report. Rome: International Board for Plant Genetic Resources. $18 \mathrm{p}$.

Chin, H. F.; Aziz, M.; Ang, B. B.; Hamzah, S. 1981. The effect of moisture and temperature on the ultrastructure and viability of seeds of Hevea brasiliensis. Seed Sci.; Technol., 9: 411-422.

Corbineau, F.; Côme, D. 1988. Storage of recalcitrant seed of four tropical species. Seed Sci.; Technol., 16: 97-103.

Edwards, T.I. 1934. Relations of germinating soybeans to temperature and length of incubation time. Plant Physiology, 9: 1-30.

Ellis, R. H.; Hong, T. D.; Roberts, E. H. 1990. An intermediate category of seed storage behaviour? 1. Coffee. Journal of Experimental Botany, 41: 1167-1174.

Ferreira, S. A. N. 1989. Efeito do tamanho da semente e do substrato sobre a emergência e vigor de plântulas de araçá-boi (Eugenia stipitata McVaugh), In: Congresso Brasileiro de Fruticultura, 10., 1989, Fortaleza. Anais... Fortaleza: Soc. Bras. Fruticultura. p. 33-40.

Flores, E. M., Rivera, D.I. 1989. Criptocotilia en algunas dicotiledoneas tropicales. Brenesia, 32: 19-26. 
Maeda, J. A., Lago, A. A. 1986. Germinação de sementes de mucuna-preta após tratamentos para superação da impermeabilidade do tegumento. Rev. Bras. Sem., 8(1): 79-84.

Maguire, J. D. 1962. Speed of germination: aid in selection and evaluation for seedling emergence and vigour. Crop Science, 2(2): 176-177.

McVaugh, R. 1956. Tropical American Myrtaceae. Fieldiana Botany, 29(3): 145-228.

Pinedo, M. H. 1981. El cultivo del araza. Iquitos: Inst. Nac. Investigación Agraria/ CIPA XVI. 15 p. (Divulgacion, 01).

Pinedo, M. H.; Ramirez N., F.; Blasco L., M. 1981. Notas preliminares sobre el araza (Eugenia stipitata), frutal nativo de la Amazonia Peruana. Lima: Inst. Nac. Investigación Agraria/IICA. 58 p. (Publ. Misc., 229).
Popinigis, F. 1977. Fisiologia da semente. Brasília: AGIPLAN. 289 p.

Roberts, E. H. 1973. Predicting the storage life of seeds. Seed Sci.; Technol., 1: 499-514.

Roberts, E. H.; King, M. W. 1980. The characteristics of recalcitrant seeds. In: Chin, H. F.; Roberts, E. H. (eds.) Recalcitrant crop seeds. Kuala Lumpur: Tropical Press SDN. BHD. p. 1-5.

Stubsgaard, F. 1989. Seed handling prior to processing. Humlebaek: Danida Forest Seed Centre. 11 p. (Lecture Note no. C-6). 